\title{
Energy Market Projections and Differentiated Carbon Abatement in the European Union*
}

\author{
Christoph Böhringer ${ }^{\mathrm{a}}$, Jesper Jensen ${ }^{\mathrm{b}, \mathrm{c}}$ and Thomas F. Rutherford ${ }^{\mathrm{b}, \mathrm{d}}$
}

May 1999

\begin{abstract}
We analyze the economic effects of the differentiated targets for carbon abatement in six European Union member states. Our recursively-dynamic model includes a detailed representation of trade and energy consumption and incorporates optimistic projections for future energy markets provided by the European Commission as the Business-as-Usual scenario. In the base case we find that the EU implementation of the Kyoto Protocol implies low overall costs and a relatively even cost distribution across member states. We also show that a less optimistic development in energy efficiency implies higher costs in all countries, especially in those with high abatement costs. Finally, we find that uniform abatement targets increase overall costs marginally but changes the cost distribution significantly, holding total EU emissions constant.
\end{abstract}

${ }^{a}$ Centre for European Economic Research (ZEW), Mannheim.

${ }^{\mathrm{b}}$ MobiDK Project, Ministry of Business and Industry, Denmark.

${ }^{\mathrm{c}}$ University of Copenhagen.

${ }^{\mathrm{d}}$ University of Colorado.

* Helpful comments have been provided by Ulrich Fahl, Glenn Harrison, Claus Kastberg Nielsen, and participants at the IPCC workshop on Economic Impacts of Annex 1 Actions on All Countries in Oslo, August 18-20, 1997. None of the views expressed here should be attributed to any of our employers or research sponsors. Corresponding author: Jesper Jensen, Ministry of Business and Industry, MobiDK Project, Slotsholmsgade 10-12, DK-1216 Copenhagen K, Denmark. E-mail: jj@em.dk 


\section{Table of Contents}

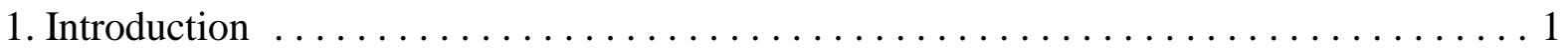

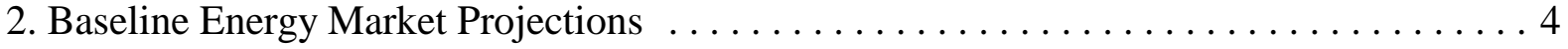

3. Analytical Framework and Baseline Calibration $\ldots \ldots \ldots \ldots \ldots \ldots \ldots \ldots \ldots \ldots \ldots \ldots \ldots \ldots \ldots \ldots \ldots$

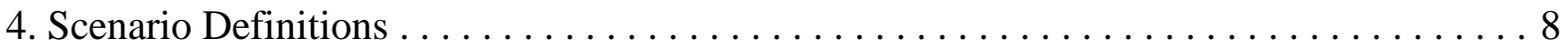

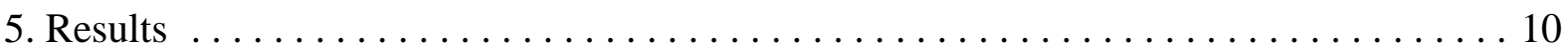

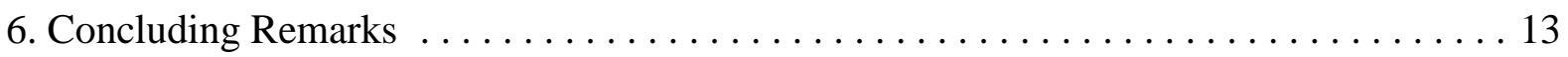

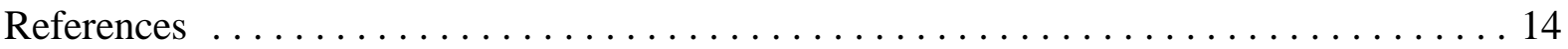

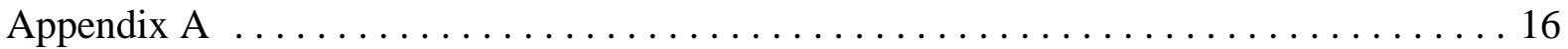

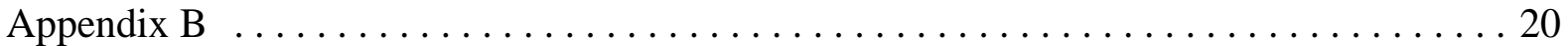

\section{List of Tables and Figures}

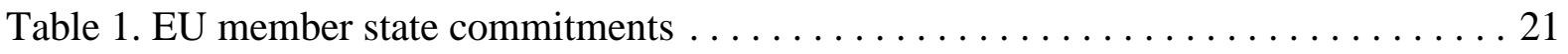

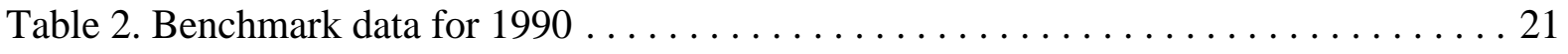

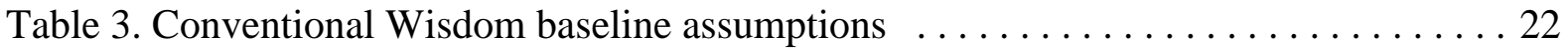

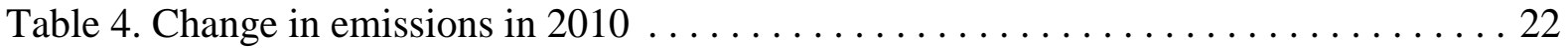

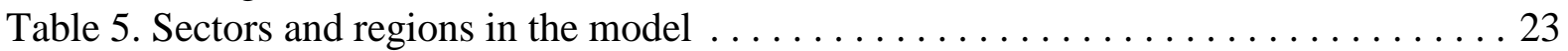

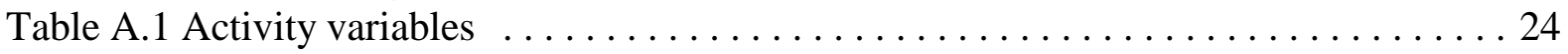

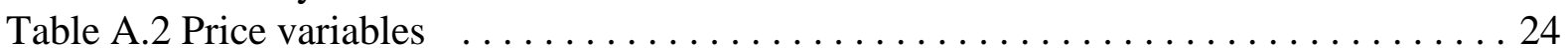

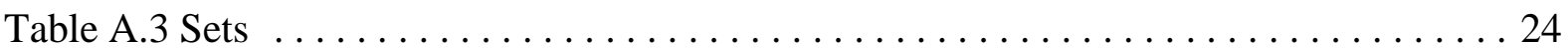

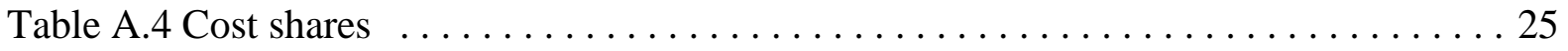

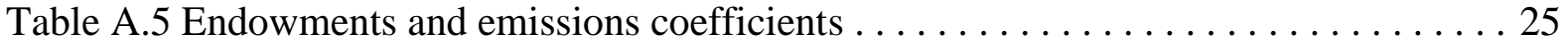

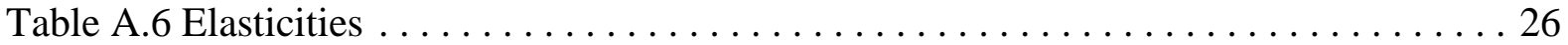

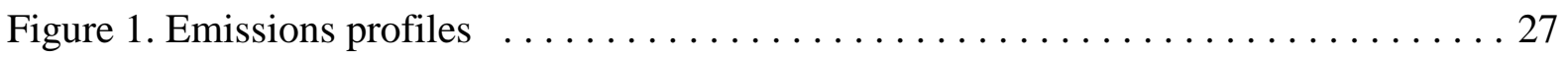

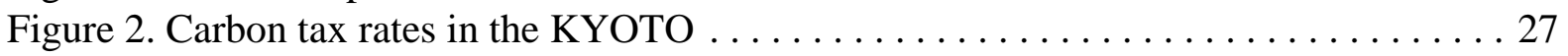

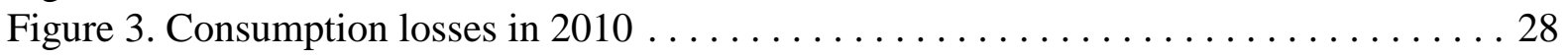

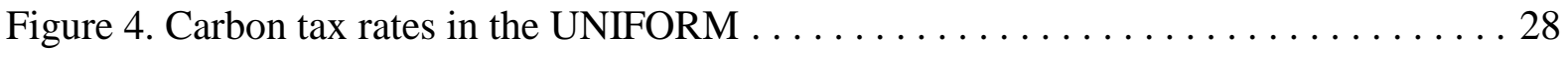

Figure 5. Carbon tax rates in the HIGH_BAU . . . . . . . . . . . . . . . . . . . . 29 


\section{Introduction}

The Kyoto Protocol documents what many believed to be impossible: negotiators for many of the world's countries agreed on emissions targets for the early part of the $21^{\text {st }}$ century. The protocol commits the Annex I countries to reduce their aggregate $\mathrm{CO}_{2}$ equivalent emissions by at least 5 percent below 1990 levels in the period 2008 to 2012. ${ }^{1}$ The agreement reflects wide differences in the willingness to accept emissions constraints: developing countries refused any commitment while the European Union (EU) at the other end agreed to an $8 \%$ overall reduction. The burden sharing negotiations subsequently continued at the EU level when the member states distributed the EU constraint internally. Table 1 shows that the country-specific targets within the EU bubble range from a $28 \%$ reduction for Luxembourg to a $27 \%$ increase for Portugal.

Does the EU bubble imply a "fair" distribution of the burden across EU member states? Economic analysis may inform this debate by translating the emissions constraints into estimates for welfare costs. The cost estimate for a given country will obviously depend on its current economic structure, such as the efficiency of the installed energy consuming technologies, the fuel mix, and trade relations with other countries. Differences in the starting point for each country may imply that the same proportional cutback results in high costs in one country and low costs in another.

The expected distribution of costs also depends on differences in the future economic development across countries. That is, the cost estimates will depend on Business-as-Usual (BaU) projections for GDP, populations, energy efficiency improvements, fuel prices, etc. High economic growth, for example, leads by itself to high energy demands and emissions.

\footnotetext{
${ }^{1}$ Article 3 in United Nations [1997]. The group of Annex I countries consists of developed economies plus economies in transition, listed in Annex I of United Nations [1992].
} 
This would increase the effective abatement requirement as the Kyoto targets refer to 1990 emissions levels and higher economic growth will therefore imply higher total abatement costs.

We analyze the agreement on differentiated $\mathrm{CO}_{2}$ abatement within the EU using the Conventional Wisdom (CW) scenario in European Commission [1996] as the BaU projection. We estimate both the total costs and the distribution of costs across EU member states and evaluate the main assumptions in the BaU projections. Specifically, we focus on the assumptions about non-uniform efficiency improvements and fuel shifting embodied in the $\mathrm{CW}$ baseline. Finally, we analyze the consequences of uniform abatement targets across the EU for total costs and the distribution of these costs.

The literature has surprisingly little to say about these issues. Most modelers are typically careful in specifying their BaU assumptions but they rarely report results from sensitivity analyses.

A couple of articles have reported results from the GEM-E3 model of analyses of carbon abatement in 11 EU member states. Conrad and Schmidt [1998a] find that a 10\% reduction in $\mathrm{CO}_{2}$ emissions from the EU implies an overall welfare loss of around $0.24 \%$ of GDP when each country has to reduce emissions by $10 \%$. Country-specific welfare effects range from a $0.06 \%$ gain in Portugal to a $0.55 \%$ loss in Denmark. Permit prices for $\mathrm{CO}_{2}$ range from US\$10 per ton in Greece to US\$47 in Denmark (assuming that ECU1 = US\$1). If emissions can be traded between countries, they estimate the permit price to US\$23 and the overall welfare loss decreases slightly to $0.21 \%$. In a similar analysis, Conrad and Schmidt [1998b] find a double dividend, i.e., 10\% lower carbon emissions and positive gross welfare effects from the policy, when they recycle permit revenues via a distortionary labor income 
$\operatorname{tax}^{2}$

Unfortunately, several important differences in model characteristics make it hard to compare the results with the present analysis. First, and most important, none of the articles based on the GEM-E3 model include $\mathrm{BaU}$ projections for GDP, $\mathrm{CO}_{2}$ emissions, energy prices, etc. Second, the GEM-E3 model includes both a labor-leisure choice and involuntary employment whereas we have a fixed labor supply. Finally, it assumes endogenous balances of trade and exogenous exchange rates. We assume that the balances of trade do not change and let the exchange rates clear the foreign exchange markets.

The present analysis makes three sets of contributions. First, to develop an explicit dynamic model, we extend an existing static, multi-sector model of six EU member states to incorporate representative agents with myopic expectations. ${ }^{3}$ Second, we develop a calibration method that allows us to use the $\mathrm{CW}$ scenario as our baseline equilibrium. Finally, we use this recursively-dynamic model to analyze the EU agreement on differentiated $\mathrm{CO}_{2}$ abatement.

The following results emerge from our simulations. First, total costs in 2010 for the EU amount to a $0.4 \%$ consumption loss and a range of costs for the member states between zero and a loss of $0.7 \% . \mathrm{CO}_{2}$ tax rates vary from $\$ 22$ per ton $\mathrm{CO}_{2}$ in Spain to $\$ 99$ in Italy. ${ }^{4}$

Second, the CW baseline embodies significant fuel shifting in electricity production in all countries and high efficiency gains in the Northern European countries. These assumptions imply large decreases in $\mathrm{CO}_{2}$ intensity and therefore low effective abatement requirements compared with our alternative baseline of uniform growth in energy efficiency

\footnotetext{
${ }^{2}$ See Capros et al. [1998] for more results from the GEM-E3 model.

${ }^{3}$ The model includes three Northern EU countries (Denmark, Germany, and the United Kingdom) and three Southern EU countries (France, Italy, and Spain).

${ }^{4}$ We recycle carbon tax revenues via lump-sum transfers to the representative agents in the model. Also, we assume that emissions cannot be traded across countries.
} 
of $1 \%$ per annum. With the latter baseline, total costs double and the range of costs changes from a low of $0.1 \%$ in Spain to a high of $2.2 \%$ in Denmark. The uniform baseline lowers the overall level of energy efficiency gains, and $\mathrm{CO}_{2}$ tax rates therefore increase in all countries. The North experiences the largest decreases in energy efficiency and therefore also the largest increases in $\mathrm{CO}_{2}$ tax rates.

Finally, we find that uniform abatement targets within the EU have a small impact on total costs, holding total EU abatement constant. The distribution of costs changes, however. Spain and France would suffer large economic losses as their abatement targets change from $+15 \%$ and $0 \%$, respectively, to $-11 \% .{ }^{5}$ Uniform targets increase costs for Spain and France, while Denmark and Germany reduce their total abatement costs by around 50\%. This scenario, although politically unrealistic, illustrates the size of the implicit transfers involved in the burden sharing negotiations.

Section 2 discusses the CW baseline for future energy markets. Section 3 describes our model and the steps involved in calibrating it to the CW baseline. Section 4 defines our policy scenarios and Section 5 presents the results. Section 6 offers concluding remarks.

\section{Baseline Energy Market Projections}

EU member states differ significantly with respect to $\mathrm{CO}_{2}$ characteristics. Table 2 presents summary statistics revealing the main differences. It focuses on the six countries in our model and shows that the selected countries jointly account for more than $80 \%$ of EU GDP and aggregate $\mathrm{EU} \mathrm{CO} \mathrm{CO}_{2}$ emissions in $1990 .{ }^{6}$ The sector contributing most to $\mathrm{CO}_{2}$ emissions is electricity, whose fuel mix differs significantly across countries. A large share

\footnotetext{
${ }^{5}$ The EU targets for the six countries amount to an average emissions cutback of $11 \%$.

${ }^{6}$ The six selected countries also emit roughly $80 \%$ of EU emissions in 2010 in the projections reported below.
} 
of nuclear-based electricity results in France having a very low $\mathrm{CO}_{2}$ intensity (ton of $\mathrm{CO}_{2}$ per GWh), whereas large shares of coal-based electricity implies higher intensities in Denmark and Germany. Finally, the rich Northern European countries also have the highest emissions per capita.

What happens to economic growth, energy prices, and $\mathrm{CO}_{2}$ emissions without climate policy? Cost estimates for the Kyoto commitments crucially depend on answers to this question. $\mathrm{CO}_{2}$ emissions are directly linked to the combustion of fossil fuels, so it follows that baseline projections of the development of the energy system play a key role in the design of the abatement policies. In particular, projections for energy efficiency improvements and the fuel mix in electricity generation are crucial for the reference level of $\mathrm{CO}_{2}$ emissions.

The CW scenario in European Commission [1996] suggests how energy markets in Europe might evolve if current policies remain in place. ${ }^{7}$ The assumptions of the $\mathrm{CW}$ scenario include smooth increases in world energy prices, no changes in current energy taxes, limited penetration of more efficient supply technologies, and no changes in energy market regulation. Renewable, $\mathrm{CO}_{2}$ free, energy production increases its share in total energy supply but fossil fuels continue to be the main source of energy. Gas and oil consumption increase, whereas the use of nuclear fuels and coal slowly decreases.

Table 3 summarizes the $\mathrm{CW}$ baseline with respect to economic growth, the development of $\mathrm{CO}_{2}$ emissions, and the fossil fuel mix in thermal electricity generation. France and the $\mathrm{CO}_{2}$ intensive Northern European countries experience the largest decreases in the $\mathrm{CO}_{2}$ intensity. Table 4 shows an increase of $6 \%$ in total $\mathrm{CO}_{2}$ emissions between 1990 and 2010 for the six EU countries covered by our model. GDP increases by around $50 \%$ in the

\footnotetext{
${ }^{7}$ See European Commission [1996; p.48-54] for the complete description of this scenario.
} 
same period, i.e., the $\mathrm{CW}$ embodies a strong decoupling of growth in GDP and $\mathrm{CO}_{2}$ emissions. The fuel shifting described above and significant efficiency improvements account for this result. Section D in Table 3 focuses on the electricity sector where the emissions intensity decreases significantly due to fuel shifting from coal to gas.

\section{Analytical Framework and Baseline Calibration}

This section presents the main characteristics of a recursively-dynamic multi-sector model of the six EU countries. We also discuss the representation of the $\mathrm{CW}$ scenario as our baseline and the subsequent sensitivity analysis of the BaU assumptions.

The model is a dynamic extension of a previous static model designed to investigate the economic implications of alternative $\mathrm{CO}_{2}$ abatement strategies for the European Union. ${ }^{8}$ Table 5 gives an overview of the regional and sectoral dis-aggregation of the current model. The choice of sectors and regions captures key dimensions in the analysis of $\mathrm{CO}_{2}$ abatement such as differences in $\mathrm{CO}_{2}$-intensity across sectors, energy goods, and bilateral trade. Appendix A provides an algebraic documentation of the model.

We have developed an explicitly dynamic model to incorporate the time paths for GDP, $\mathrm{CO}_{2}$ emissions, energy prices, etc., for the $\mathrm{CW}$ scenario. We assume constant, regionspecific marginal propensities to save consistent with a growth rate of $2 \%$ per year in all countries. The path for the economy is represented by a set of connected equilibria where the current period's saving augments capital stocks in the next period. Consumers allocate income between present and future consumption subject to a fixed marginal propensity to

\footnotetext{
${ }^{8}$ See Böhringer, Ferris, and Rutherford [1998] for an algebraic formulation of the static model, and Böhringer, Harrison, and Rutherford [1998] for an application of the static model to carbon abatement and burden sharing within the EU.
} 
save and investment adjusts passively to savings. The intra-period model corresponds to the previous static model. Base year data determine the parameters of the functional forms from a given set of quantities, prices and benchmark elasticities.

A simple calibration of the model along the time path would typically involve calibration to a steady-state where all physical quantities (including $\mathrm{CO}_{2}$ emissions) grow at an exogenous uniform rate while relative prices remain unchanged. The virtue of a steadystate baseline is that it provides a transparent reference path for the evaluation of policy interference: any structural change in the counterfactual can be attributed to the new policy.

In the present analysis we want to incorporate exogenous information from the $\mathrm{CW}$ baseline on non-uniform growth rates in GDP, fossil fuel production, fuel mixes in electricity generation, changes in world market energy prices and $\mathrm{CO}_{2}$ emission profiles. The calibration procedure involves two steps. ${ }^{9}$ First, we scale factor endowments, fuel demands in electricity production and world market energy prices. Second, we incorporate autonomous energy efficiency improvements (AEEI) to match the aggregate emissions profiles. AEEI represents energy efficiency improvements in addition to energy demand reductions caused by changes in energy prices. The European Commission [1996] mentions research or changes in public standards as sources of efficiency improvements.

After the calibration the model represents the $\mathrm{CW}$ baseline as an equilibrium solution. Figure 1 shows the $\mathrm{CW} \mathrm{CO}_{2}$ emissions profile with an alternative $\mathrm{BaU}$ path labeled LOW_AEEI. The latter deviates from CW only with respect to the assumption about AEEI and exogenous fuel shifting in the electricity sector. In the LOW_AEEI baseline we solve the model with all AEEI equal to $1 \%$ p.a. and let relative prices determine the fuel mix in the

\footnotetext{
${ }^{9}$ See appendix B for details of the calibration procedure.
} 
electricity sector.

Table 4 shows that aggregate $\mathrm{CO}_{2}$ emissions in 2010 exceed the 1990 level by $6 \%$ in the CW baseline and 20\% in the LOW_AEEI baseline. Two factors explain most of this difference. First, the $\mathrm{CW}$ baseline implies more fuel shifting from coal to gas in the electricity sector than the model can explain with changes in relative prices. Second, AEEI exceeds $1 \%$ p.a. in many cases in the $\mathrm{CW}$ baseline, and in particular Germany and Denmark are expected to experience large energy efficiency improvements. ${ }^{10}$

We do not regard the LOW_AEEI baseline as more realistic than the CW baseline that is based on a compilation of detailed country studies. Rather we think of it as a sensitivity analysis that illustrates the implications of the $\mathrm{CW}$ assumptions about relatively high values for AEEI and fuel shifting in electricity generation.

\section{Scenario Definitions}

Our numerical analysis distinguishes three $\mathrm{CO}_{2}$ abatement scenarios: KYOTO, UNIFORM, and HIGH_BAU. The KYOTO scenario implements the EU agreement on differentiated emissions reductions that distributes the $8 \%$ Kyoto commitment by the EU across member states. ${ }^{11}$ The KYOTO scenario, which employs the CW baseline as the BaU, represents our base case.

The differentiated cutbacks amount to an average reduction of $11 \%$ for the six countries in our model. The UNIFORM scenario requires all six countries to reduce emissions uniformly by $11 \%$ and it also uses the $\mathrm{CW}$ baseline. This scenario allows us to analyze the implications of the differentiated cutbacks, holding total EU emissions constant.

\footnotetext{
${ }^{10}$ A poll of 22 experts reported in Manne and Richels [1994] results in an average AEEI value of 0.7\% p.a.

${ }^{11}$ See EU [1998].
} 
In the HIGH_BAU scenario we apply the differentiated cutbacks used in the KYOTO scenario but employ different BaU assumptions: All AEEI equal 1\% p.a. and relative prices determine the fuel mix in electricity production, i.e., the LOW_AEEI baseline.

The last three columns in Table 4 show the effective abatement requirements in 2010 in the three scenarios. As expected, the choice of baseline has a considerable impact on the required abatement effort.

Several characteristics are common to all three scenarios. First, all scenarios result in the same aggregate $\mathrm{CO}_{2}$ abatement for the six EU countries in the model. We ignore the issue of carbon leakage and we thus assume that the EU policies do not lead to higher emissions outside the EU. This allows us to compare the results without considering the benefits from $\mathrm{CO}_{2}$ abatement, i.e., we only consider the gross costs.

Second, we use the same cutback profile for aggregate EU emissions in all scenarios. Specifically, we assume a stabilization of aggregate emissions in the year 2000 at 1990 levels and a linear cutback between 2000 and 2010. In other words, all countries have to meet half their 2010 commitments by 2005 .

Third, we do not allow for trade in emissions across countries. Emissions can be traded across sectors within a given country, but all emissions reductions must take place domestically and no emissions can be purchased abroad.

Fourth, we incorporate the emissions constraints as a resource constraint in the model where we interpret the shadow price on the constraint as the $\mathrm{CO}_{2}$ tax rate. The representative consumer in each region collects all the revenue and the provision of public goods stays constant.

The model solves for counterfactual equilibria in five-year steps starting in the year 2000. We report consumption losses and $\mathrm{CO}_{2}$ tax rates in Figures 2-5. Consumption losses 
are calculated as the percentage change in final consumption relative to the relevant baseline and $\mathrm{CO}_{2}$ tax rates (marginal abatement costs) are reported in US\$1990 per metric ton of $\mathrm{CO}_{2}$.

\section{Results}

The effective emissions targets provide the starting point for the interpretation of the results (see Table 4) and we begin with our base case, the KYOTO scenario. Figure 2 shows that the high abatement countries Denmark, Germany, Italy, and the UK face high carbon taxes whereas the low targets for France and Spain require relatively low tax rates. The stabilization of Germany's emissions in the year 2000 does not require any carbon tax as the unification caused a significant drop in emissions from 1990 to 1995.

The carbon taxes cause efficiency losses and Figure 3 summarizes the results for consumption losses in 2010. Overall, the KYOTO scenario implies a total consumption loss of $0.4 \%$ in 2010 and the distribution of consumption losses reflects the differences in tax rates as explained above. The high abatement countries Germany and Denmark also bear the highest consumption losses while France and Spain meet their targets at very low costs. Two effects work in opposite directions to produce the negligible consumption loss for Spain. First, the low tax rate induces a small efficiency cost. Second, Spain experiences a gain as its production becomes more competitive compared with its EU competitors because tax rates are much higher in the rest of the EU.

All three Southern countries (Spain, Italy and France) face higher targets in the UNIFORM scenario compared with the KYOTO scenario, whereas the Northern countries' emissions constraints become less binding. This implies a significantly different pattern of carbon taxes as shown in Figure 4. Low efficiency gains and relatively little fuel shifting in the CW baseline imply that the uniform targets result in relatively high effective targets in the 
Southern countries. These countries therefore experience the highest tax rates.

Figure 3 shows that total EU costs increase marginally in the UNIFORM scenario, but the cost distribution changes dramatically. Compared to the KYOTO scenario, the costs for Denmark and Germany decrease by around 50\% whereas the costs increase in all Southern countries. Spain jumps from virtually zero costs to a $0.9 \%$ consumption loss. While this scenario may be politically irrelevant, it shows the implicit transfers involved in the negotiations about the EU bubble. Total EU emissions are identical in the KYOTO and the UNIFORM scenarios but the distribution of emissions allowance differs. The larger the allowance, the lower the carbon tax rate and the smaller the efficiency cost.

Both the KYOTO and the UNIFORM scenarios use the CW baseline. The LOW_AEEI baseline in Figure 1 shows that baseline emissions exceed CW emissions by $14 \%$ of 1990 emissions when AEEI equals $1 \%$ p.a. and relative prices determine the fuel mix in electricity production. The last column in Table 4 shows that the EU commitment in Kyoto now requires an effective total cutbacks of $26 \%$ compared with the LOW_AEEI baseline. The effective targets increase for all countries and the Northern countries experience the highest increases.

Figure 5 shows, as expected, that higher carbon taxes follow the more stringent targets in the HIGH_BAU scenario. Tax rates increase between 50 and $100 \%$ for all countries except Italy. ${ }^{12}$ The higher rates cause higher consumption losses in all countries and increase the range of costs from $0.1 \%$ in Spain to $2.2 \%$ in Denmark. Put differently, if the optimistic CW baseline fails to materialize and future European energy markets develop more uniformly, the differentiated targets will imply a less equitable distribution of abatement

\footnotetext{
${ }^{12}$ Italy's CW baseline emissions grow relatively slowly because of the absence of fuel shifting in the electricity sector and low efficiency improvements.
} 
costs.

Finally, we relax the assumption about no trade in emissions across countries. Specifically, we assume that all six countries can trade emissions freely such that the same carbon tax rate applies in all countries. The quantitative effects of this change turns out to be small and we thus conclude that our results are robust with respect to the assumption about emissions trading.

In our model, trade in emissions leads to equalization of the domestic carbon tax rates and this influences the results via two channels: the distortionary effects of carbon taxes change and the values of the emission endowments change. Countries that previously had carbon tax rates below the new common tax rate will experience higher distortionary costs from higher carbon tax rates but they will also find their emission endowments more valuable. Conversely, countries with high carbon tax rates will have lower distortionary costs but also lower carbon tax revenues. Emissions trading may also change the international incidence of carbon taxes as the burden of the taxes in a given country now get shifted differently to foreign and domestic agents.

We use the model to trace all these effects and the main results can be summarized as follows. ${ }^{13}$ First, some countries gain slightly, others experience small losses and the overall EU costs decrease marginally. That is, trading within the EU imply small total costs' savings. Intuitively, the differences in carbon tax rates before we allow for trading are significant but not large, and this effectively limits the extent of emissions trading. Spain, a net exporter, and Germany, a net importer, gain most from emissions trading. Second, we also conclude that our results regarding energy market projections are robust. We find that the effects of

\footnotetext{
${ }^{13}$ The tables with results are available from the authors.
} 
changing projections are similar to the no trading case, although the effects mostly are quantitatively smaller. Finally, uniform abatement targets continue to show large implicit transfers from Northern European member states to Southern member states. This result hold although the differences in consumption losses decrease between differentiated and uniform abatement targets.

\section{Concluding Remarks}

Burden sharing dominates the climate policy negotiations since the participating countries must view the expected distribution of costs as "fair" in order for them to be politically acceptable. Negotiators point to both the countries' current economic structure and projections for the future economic development when they propose "fair" abatement targets.

We have analyzed the EU agreement on differentiated greenhouse gas abatement with a particular focus on the role of baseline projections for future energy markets. We used a dynamic multi-sector, multi-region general equilibrium model for the EU. The following insights emerge from our policy simulations:

(i) The overall costs of the EU bubble following its Kyoto commitment are low when we use the CW scenario provided by the European Commission as the baseline. The range of costs across member states is narrow, and the necessary $\mathrm{CO}_{2}$ taxes in the year 2010 are below US\$100 per ton $\mathrm{CO}_{2}$ in all countries.

(ii) The $\mathrm{CW}$ baseline implies significant fuel shifting in electricity generation and large energy efficiency improvements by historical standards. If the projected, strong decoupling of GDP growth and $\mathrm{CO}_{2}$ fails to materialize, both the overall $\mathrm{CO}_{2}$ abatement costs and the range of costs across member states may increase significantly. 
(iii) Uniform abatement hardly increases total costs but it changes the cost distribution between countries considerably. We show that the EU bubble implicitly involves large economic transfers from the Northern European member states to the Southern European member states. This may be consistent with a higher willingness to pay for emissions reductions in the Northern countries.

Finally, we close with a caveat. Our model captures important aspects of bilateral trade and energy consumption in the EU. It is nonetheless a crude approximation of the real world's technologies, preferences, factor endowments, etc., and we therefore caution against too literal an interpretation of the numerical results.

\section{References}

Böhringer, Christoph; Ferris, Michael; and Rutherford, Thomas F., "Alternative $\mathrm{CO}_{2}$ abatement strategies for the European Union," in Braden and Proost [1998].

Böhringer, Christoph; Harrison, Glenn W.; and Rutherford, Thomas F., "Sharing the Burden of Carbon Abatement in the European Union," Working Paper 98-5 (Boulder: University of Colorado, 1998).

Braden, John B. and Proost, Stef (eds.), Climate Change, Transport and Environmental Policy - Empirical Applications in a Federal System (London: Edward Elgar, 1998).

Capros, Pantelis; Georgakopoulos, Panayiotis; Zografakis, Stavros; van Regemorter, Denise; and Proost, Stef, "Coordinated versus non-coordinated European energy/carbon tax solutions analysed with GEM-E3 linking the EU-12 countries," in Braden and Proost [1998].

Conrad, Klaus and Schmidt, Tobias F.N., "National economic impacts of an EU environmental policy: an applied general equilibrium analysis," 1998a, in Braden and Proost [1998].

Conrad, Klaus and Schmidt, Tobias F.N., "Economic Effects of an Uncoordinated Versus a Coordinated Carbon Dioxide Policy in the European Union: An Applied General Equilibrium Analysis," Economic Systems Research 10(2), 1998b, 161-182.

European Commission, Energy in Europe - European Energy to 2020 - A Scenario Approach (Brussels: European Commission, 1996).

European Commission, European Economy: The economics of limiting $\mathrm{CO}_{2}$ emissions, special edition No.1 (Brussels: European Commission, 1992).

European Union, Community strategy on climate change - Council Conclusions. Communiqué from the $2106^{\text {th }}$ Council meeting 16-17 June 1998 (Luxembourg: European Union, 1998). 
Inter-Governmental Panel on Climate Change (IPCC), Climate Change 1995 (New York: Cambridge University Press, 1997).

Manne, Alan S. and Richels, Richard G., "The Costs of Stabilizing Global $\mathrm{CO}_{2}$ Emissions: A Probalistic Analysis Based on Expert Judgements," The Energy Journal 15(1), 1994, 31-56.

United Nations, Kyoto Protocol, FCCC/CP/1997/L.7/Add.1, (Geneva: United Nations, 1997).

United Nations, United Nations Framework Convention on Climate Change (Geneva: United Nations, 1992).

Weyant, John P., "Costs of Reducing Global Carbon Emissions,” Journal of Economic Perspectives 7(4), 1993, 27-46. 


\section{Appendix A}

This appendix provides an algebraic summary of the equilibrium conditions for the model. First, we present the main assumptions of the model and introduce notation. We then present the algebraic model.

Nested constant elasticity of substitution (CES) functions characterize the use of inputs in production and all production exhibits non-increasing returns to scale. Goods are produced with capital, labor, energy, and materials and all sectors produce a single. We therefore use 'goods' and 'sectors' interchangeably. Firms behave competitively and all markets are perfectly competitive.

A representative agent (RA) in each region is endowed with three primary factors: natural resources (used for fossil fuel production), labor and initial stock of capital. Nested CES functions characterize consumption by the RA (final demand) and the RA has myopic expectations, i.e., he is not forward-looking. The supplies of labor and natural resources are exogenous and labor and capital can move freely across sectors within each region but cannot move between regions. Natural resources are sector specific.

All goods, except coal, crude oil and gas, are differentiated by region of origin. Constant elasticity of transformation functions characterize the differentiation of production between production for the domestic markets and the export markets. Regarding imports, nested CES functions characterize the choice between imported and domestic varieties of the same good (Armington).

The rest of the world is represented with horizontal export demand and import supply schedules, i.e., the EU regions behave as a small open economy. The balance of payments for each region with respect to the rest of the world is exogenous.

A constant marginal propensity to save characterizes the RA's allocation of income 
between savings, i.e., investments and current consumption. Investments begin to provide capital services one period after installation and the capital stock depreciates at a constant rate. Growth augments the labor endowment at a constant rate.

Finally, lump sum transfers finance the exogenous government demands and the government in each region transfers all carbon tax revenues to the RA in the region.

The myopic expectations imply that the economies effectively reduce to a set of connected equilibria, where the current period's investments augments the capital stock in the next period. That is, all equilibrium conditions are strictly intra-period and we can thus omit time indices with out loss of generality.

We characterize the model with two classes of equilibrium conditions: zero profit conditions and market clearance conditions. The former determines activity levels and the latter determines price levels. Tables A.1 and A.2 show the activity and the price levels in the model and Table A.3 explains the set notation.

The algebraic exposition of the model begins with the profit functions. We then derive the market clearance conditions by exploiting Shephard's lemma: differentiation of the profit functions with respect to input and output prices yields compensated demand and supply functions. The exposition and our empirical implementation uses calibrated CES functions as the key element. Tables A.4-A.6 explain the notation for the calibrated model parameters.

Zero profit conditions:

1. Production of goods except fossil fuels:

$$
\Pi_{i r}^{Y}=\left(\sum_{s} \theta_{i r s}^{X} p_{i s}^{1-\eta}+\theta_{u}^{X} p^{w^{1-\eta}}\right)^{\frac{1}{1-\eta}}-\sum_{j \notin E} \theta_{j i r} p_{Y j r}^{A}-\theta_{i r}^{K L E}\left[\theta_{i r}^{E} p_{i r}^{E^{1-\sigma_{K L E}}}+\left(1-\theta_{i r}^{E}\right)\left(w_{r}^{\alpha_{i r}^{L}} v_{r}^{1-\alpha_{i r}^{L}}\right)^{1-\sigma_{K L E}}\right]^{1} \frac{1}{1-\sigma_{K L E}}=0, i \notin F F
$$


2. Production of fossil fuels:

$$
\Pi_{i r}^{Y}=p^{w}-\left[\theta_{i r}^{Q} q_{i r}^{1-\sigma_{Q}}+\left(1-\theta_{i r}^{Q}\right)\left(\delta_{i r}^{L} w_{r}+\delta_{i r}^{K} v_{r}+\sum_{j} \theta_{j i r}^{F F} p_{Y j r}^{A}\right)^{1-\sigma_{Q}}\right]^{\frac{1}{1-\sigma_{Q}}}=0, i \in F F
$$

3. Sector-specific energy aggregate:

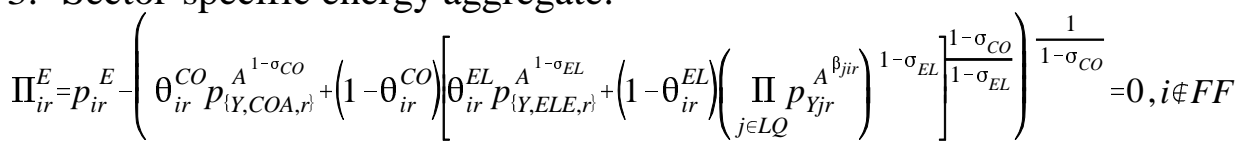

4. Armington aggregate except fossil fuels:

$$
\Pi_{d i r}^{A}=p_{d i r}^{A}-\left[\left(\theta_{d i r}^{A} p_{i r}^{1-\sigma_{A}}+\left(1-\theta_{d i r}^{A}\right) p_{i r}^{M^{1-\sigma_{A}}}\right)^{\frac{1}{1-\sigma_{A}}}+t_{r}^{c} a_{d i r}^{c}\right]=0, i \notin F F
$$

5. Armington aggregate for fossil fuels

$$
\Pi_{d i r}^{A}=p_{d i r}^{A}\left[p^{w}+t_{r}^{c} a_{d i r}^{c}\right]=0, i \in F F
$$

6. Aggregate imports across import regions except fossil fuels:

$$
\Pi_{i r}^{M}=p_{i r}^{M}-\left(\theta_{i r}^{W} p^{w^{1-\sigma_{M}}}+\sum_{s} \theta_{i s}^{M} p_{i s}^{1-\sigma_{M}}\right)^{\frac{1}{1-\sigma_{M}}}=0, i \notin F F
$$

7. Investment:

$\Pi_{r}^{I}=p_{r}^{I}-\sum_{i} \theta_{i r}^{I} p_{\text {Iir }}^{A}=0$

8. Public good production:

$$
\Pi_{r}^{G}=p_{r}^{G}-\sum_{i} \theta_{i r}^{G} p_{\text {Iir }}^{A}=0
$$

9. Household consumption demand:

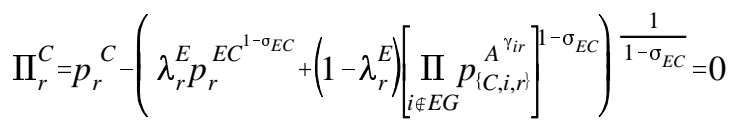

10. Household energy demand:

$$
\Pi_{r}^{E C}=p_{r}^{E C}\left(\lambda_{r}^{E L} p_{\{C, E L E, r\}}^{1-\sigma_{E L}}+\left(1-\lambda_{r}^{E L}\right)\left[\left(\sum_{\left.i \in E G\right|_{\mid E L E]}} \lambda_{i r}^{E} p_{\{C, i, r\}}^{A^{1-\sigma_{N E}}}\right)^{\frac{1}{1-\sigma_{N E}}}\right]^{1-\sigma_{E L}}\right)^{\frac{1}{1-\sigma_{E L}}}=0
$$

\section{Market Clearance Conditions}

11.Labor:

$\overline{L_{r}}=\sum_{i} Y_{i r} \frac{\partial \Pi_{i r}^{Y}}{\partial w_{r}}$

12. Capital:

$\overline{K_{r}}=\sum_{i} Y_{i r} \frac{\partial \Pi_{i r}^{Y}}{\partial v_{r}}$ 
13. Natural resources:

$\overline{Q_{i r}}=Y_{i r} \frac{\partial \Pi_{i r}^{Y}}{\partial q_{i r}} \quad i \in F F$

14. Output except fossil fuels:

$Y_{i r} \frac{\partial \Pi_{i r}^{Y}}{\partial p_{i r}}=\sum_{d, j} A_{d j r} \frac{\partial \Pi_{d j r}^{A}}{\partial p_{i r}}+\sum_{s} M_{i s} \frac{\partial \Pi_{i s}^{M}}{\partial p_{i r}}, i \notin F F$

15. Sector specific energy aggregate:

$E_{i r}=Y_{i r} \frac{\partial \Pi_{i r}^{Y}}{\partial p_{i r}^{E}}$

16. Import aggregate except fossil fuels:

$M_{i r}=\sum_{d} A_{d i r} \frac{\partial \Pi_{d i r}^{A}}{\partial p_{i r}{ }^{M}}, i \notin F F$

17. Armington aggregate:

$A_{d i r}=\sum_{j} Y_{j r} \frac{\partial \Pi_{j r}^{Y}}{\partial p_{d i r}^{A}}+C_{r} \frac{\partial \Pi_{r}^{C}}{\partial p_{d i r}^{A}}+I_{r} \frac{\partial \Pi_{r}^{I}}{\partial p_{d i r}^{A}}+G_{r} \frac{\partial \Pi_{r}^{G}}{\partial p_{d i r}^{A}}$

18. Household consumption:

$p_{r}{ }^{C} C_{r}=\left(1-\mu_{r}\right)\left[w_{r} \overline{L_{r}}+v_{r} \bar{K}_{r}+\sum_{j \in F F} q_{j r} \overline{Q_{j r}}+t_{r}^{c} \bar{Z}_{r}-p_{r}^{G} \overline{G_{r}}-p^{w} \overline{B_{r}}\right]$

19. Savings:

$p_{r}^{I} I_{r}=\mu_{r}\left[w_{r} \bar{L}_{r}+v_{r} \bar{K}_{r}+\sum_{j \in F F} q_{j r}{\overline{Q_{j r}}}_{r}+t_{r}^{c} \bar{Z}_{r}-p_{r}^{G} \bar{G}_{r}-p^{w} \overline{B_{r}}\right]$

20. Aggregate household energy consumption:

$D_{r}=C_{r} \frac{\partial \Pi_{r}^{C}}{\partial p_{r}^{E C}}$

21. Balance of Payments:

$\sum_{i} Y_{i r} \frac{\partial \Pi_{i r}^{Y}}{\partial p^{w}}+\sum_{r} \bar{B}_{r}=\sum_{i \notin F F} \frac{\partial \Pi_{i r}^{M}}{\partial p^{w}}+\sum_{i \in F F, d} \frac{\partial \Pi_{d i r}^{A}}{\partial p^{w}}$

22. $\mathrm{CO}_{2}$ emissions:

$\overline{Z_{r}}=\sum_{d, i} A_{d i r} \frac{\partial \Pi_{d i r}^{A}}{\partial t_{r}^{c}}$

23. Government output:

$\overline{G_{r}}=G_{r}$ 


\section{Appendix B}

This appendix describes the calibration of our model to the CW baseline. In two steps, we incorporate exogenous information on non-uniform growth rates in GDP, fossil fuel production, fuel mixes in electricity generation, changes in world market energy prices and $\mathrm{CO}_{2}$ emission profiles.

First, we fix the time profile of fossil fuel supplies from the EU to the exogenous baseline projections by making supplies inelastic and scaling sector-specific resources with the exogenous growth rates in fossil fuel production. This allows us to partially control the emission profile from the supply side (except the effects of imported fuels). On the demand side, we incorporate AEEI on the energy demands by consumers and production activities. We also incorporate exogenous fuel shifting in the electricity sector and exogenous, regionspecific GDP growth rates determine the size of labor endowments. Finally, we adjust import demand and export supply functions with respect to the rest of the world to account for exogenous changes in world market energy prices. We solve the model with these changes in parameter values and obtain country-specific estimates for $\mathrm{CO}_{2}$ emissions.

These estimates deviate from the $\mathrm{CO}_{2}$ emissions profile in the $\mathrm{CW}$ baseline by changes in the fossil fuel supplies from the rest of the world. We therefore include a second step in the calibration procedure where we scale the non-electric AEEI factors to reduce energy demands and, hence, $\mathrm{CO}_{2}$ emissions. The scaling takes place country by country to match the model as close as possible to the $\mathrm{CW}$ emissions profiles. We solve the model again to verify that it represents the $\mathrm{CW}$ baseline as an equilibrium solution. Finally, we use the equilibrium prices to calibrate the fossil fuel production functions to a price elasticity of supply equal to one. 
Table 1. EU member state commitments

\begin{tabular}{lc}
\hline Member States & Commitments in accordance with the Kyoto Protocol \\
\hline Belgium & $-7.5 \%$ \\
Denmark & $-21 \%$ \\
Germany & $-21 \%$ \\
Greece & $+25 \%$ \\
Spain & $+15 \%$ \\
France & $0 \%$ \\
Ireland & $+13 \%$ \\
Italy & $-6.5 \%$ \\
Luxembourg & $-28 \%$ \\
Netherlands & $-6 \%$ \\
Austria & $-13 \%$ \\
Portugal & $+27 \%$ \\
Finland & $0 \%$ \\
Sweden & $+4 \%$ \\
United Kingdom & $-12.5 \%$ \\
EU & $-8 \%$ \\
\hline Source: Appendix 1 in EU [1998]. & \\
\hline
\end{tabular}

Table 2. Benchmark data for 1990

\begin{tabular}{|c|c|c|c|c|c|c|c|c|}
\hline \multicolumn{9}{|l|}{ A. Summary statistics } \\
\hline & $\mathrm{DE}$ & DK & ES & IT & FR & UK & REU & EU \\
\hline GDP ( $\%$ of EU total) & 24 & 2 & 6 & 15 & 19 & 16 & 18 & 100 \\
\hline $\mathrm{CO}_{2}(\%$ of EU total $)$ & 32 & 2 & 7 & 13 & 12 & 18 & 17 & 100 \\
\hline $\mathrm{CO}_{2}$ (ton per capita) & 13 & 11 & 5 & 7 & 7 & 10 & 8 & 9 \\
\hline Electricity (ton of $\mathrm{CO}_{2} / \mathrm{GWh}$ ) & 653 & 892 & 429 & 565 & 105 & 686 & 260 & 462 \\
\hline \multicolumn{9}{|l|}{ B. $\mathrm{CO}_{2}$ emissions sources (\%) } \\
\hline \multirow[b]{2}{*}{ Electrici } & $\mathrm{DE}$ & DK & ES & IT & FR & UK & REU & EU \\
\hline & 36 & 43 & 31 & 30 & 12 & 38 & 23 & 30 \\
\hline Energy production & 3 & 2 & 6 & 5 & 5 & 5 & 5 & 4 \\
\hline Industry & 20 & 11 & 21 & 20 & 23 & 14 & 24 & 20 \\
\hline Transport & 17 & 26 & 32 & 25 & 34 & 24 & 26 & 24 \\
\hline Final demand & 24 & 17 & 10 & 20 & 26 & 19 & 22 & 21 \\
\hline Total & 100 & 100 & 100 & 100 & 100 & 100 & 100 & 100 \\
\hline \multicolumn{9}{|c|}{$\begin{array}{l}\text { Note: The Rest of the European Union (REU) includes Austria, Belgium, Finland, Luxembourg, Greece, } \\
\text { Ireland, the Netherlands, Portugal and Sweden. Table } 5 \text { explains the other region acronyms. }\end{array}$} \\
\hline \multicolumn{9}{|c|}{ Source: Calculations based on European Commission [1996; 161-209]. } \\
\hline
\end{tabular}


Table 3. Conventional Wisdom baseline assumptions

\begin{tabular}{|c|c|c|c|c|c|c|c|}
\hline \multicolumn{8}{|c|}{ A. Average GDP growth rate (\% p.a.) } \\
\hline & $\mathrm{DE}$ & DK & ES & FR & IT & UK & $\mathrm{EU}$ \\
\hline $1990-2000$ & 2.8 & 2.6 & 2.1 & 1.9 & 1.8 & 1.9 & 2.1 \\
\hline $2000-2010$ & 2.3 & 2.0 & 2.7 & 2.5 & 2.0 & 2.1 & 2.3 \\
\hline \multicolumn{8}{|c|}{ B. Average $\mathrm{CO}_{2}$ growth rate (\% p.a.) } \\
\hline & $\mathrm{DE}$ & DK & ES & FR & IT & UK & EU \\
\hline 1990-2000 & -0.2 & 1.9 & 0.6 & 0.6 & 0.9 & 0.3 & 0.3 \\
\hline 2000-2010 & 0.1 & -0.8 & 1.4 & 0.1 & 0.5 & 0.2 & 0.5 \\
\hline \multicolumn{8}{|c|}{ C. Implied average improvement in $\mathrm{CO}_{2}$ intensity (\% p.a.) } \\
\hline & $\mathrm{DE}$ & DK & ES & FR & IT & UK & EU \\
\hline $1990-2000$ & 2.9 & 0.7 & 1.5 & 1.3 & 0.9 & 1.5 & 1.8 \\
\hline $2000-2010$ & 2.1 & 2.7 & 1.3 & 2.4 & 1.5 & 1.9 & 1.8 \\
\hline \multicolumn{8}{|c|}{ D. Average growth rates for fossil fuel inputs to electricity generation (\% p.a.) } \\
\hline & $\mathrm{DE}$ & DK & ES & FR & IT & UK & EU \\
\hline \multicolumn{8}{|l|}{$1990-2000$} \\
\hline Coal & -0.8 & 1.6 & -4.9 & 3.3 & 6.7 & -4.2 & -1.0 \\
\hline Oil & 8.0 & 9.3 & 3.3 & -13.1 & -0.9 & -6.3 & -0.1 \\
\hline Gas & 4.2 & 25.4 & 25.8 & 6.5 & 2.2 & 31.3 & 8.3 \\
\hline \multicolumn{8}{|l|}{$2000-2010$} \\
\hline Coal & -0.5 & -3.4 & 2.1 & -11.9 & -0.8 & -6.0 & -1.2 \\
\hline Oil & -1.5 & -5.1 & -1.2 & -14.3 & -5.4 & 3.4 & -2.2 \\
\hline Gas & 6.0 & 7.3 & 7.9 & 10.9 & 8.5 & 6.1 & 6.6 \\
\hline
\end{tabular}

Table 4. Change in emissions in 2010

\begin{tabular}{|c|c|c|c|c|c|c|}
\hline & \multicolumn{3}{|c|}{ Relative to 1990 emissions } & \multicolumn{3}{|c|}{ Relative to $\mathrm{BaU}$ emissions in 2010} \\
\hline & Kyoto & $\mathrm{CW}$ & LOW_AEEI & KYOTO & UNIFORM & HIGH_BAU \\
\hline EU & $-11 \%$ & $6 \%$ & $20 \%$ & $-16 \%$ & $-16 \%$ & $-26 \%$ \\
\hline DE & $-21 \%$ & $-1 \%$ & $18 \%$ & $-21 \%$ & $-10 \%$ & $-33 \%$ \\
\hline DK & $-21 \%$ & $12 \%$ & $45 \%$ & $-30 \%$ & $-21 \%$ & $-45 \%$ \\
\hline UK & $-12.5 \%$ & $5 \%$ & $22 \%$ & $-17 \%$ & $-15 \%$ & $-28 \%$ \\
\hline FR & $0 \%$ & $7 \%$ & $19 \%$ & $-6 \%$ & $-17 \%$ & $-16 \%$ \\
\hline IT & $-6.5 \%$ & $15 \%$ & $15 \%$ & $-18 \%$ & $-22 \%$ & $-18 \%$ \\
\hline ES & $15 \%$ & $22 \%$ & $28 \%$ & $-6 \%$ & $-27 \%$ & $-10 \%$ \\
\hline
\end{tabular}


Table 5. Sectors and regions in the model

\begin{tabular}{l}
\hline Production sectors (Eurostat's R59 code in brackets): \\
\hline 1.Coal $(031,033)$ \\
2.Crude oil (071) \\
3.Refined oil (073) \\
4.Natural and manufactured gases $(075,098)$ \\
5.Electricity and steam $(097,099)$ \\
6.Agriculture (010) \\
7.Iron and steel (135,136) \\
8.Chemical products $(170)$ \\
9.Non-ferrous metals $(137)$ \\
10.Non-metallic minerals $(151,153,155,157)$ \\
11.Machinery (190,210,230,250) \\
12.Transport equipment $(270,290)$ \\
13.Paper pulp and printing $(471,473)$ \\
14.Wood and wood products $(450)$ \\
15.Food processing beverages and tobacco $(310,330,350,370,390)$ \\
16.Textiles and leather $(410,430)$ \\
17.Transport $(611,613,617,631,633,650)$ \\
18.Other industries $(095,490,510,530,550,570,590,670,690,710,730,750,770,790,810,850,890,930)$ \\
\hline Regions $\quad$ Germany \\
\hline 1.DE \\
2.DK Denmark \\
3.ES Spain \\
4.FR France \\
5.IT Italy \\
6.UK United Kingdom \\
\hline
\end{tabular}


Table A.1 Activity variables

$\begin{array}{ll}Y_{i r} & \text { Production in sector } i \text { and region } r \\ E_{i r} & \text { Aggregate energy input in sector } i \text { and region } r \\ M_{i r} & \text { Aggregate imports in good } i \text { and region } r \\ A_{d i r} & \text { Armington aggregate for demand category } d \text { of good } i \text { in region } r \\ I_{r} & \text { Aggregate investment in region } r \\ G_{r} & \text { Aggregate public output in region } r \\ C_{r} & \text { Aggregate household consumption in region } r \\ D_{r} & \text { Aggregate household energy consumption in region } r\end{array}$

Table A.2 Price variables

\begin{tabular}{cl}
\hline$p_{i r}$ & Output price of good $i$ produced in region $r$ \\
$p_{i r}{ }^{E}$ & Price of aggregate energy in sector $i$ and region $r$ \\
$p_{i r}{ }^{M}$ & Import price aggregate for good $i$ imported to region $r$ \\
$p_{d i r}{ }^{I}$ & Price of Armington aggregate for demand category $d$ of good $i$ in region $r$ \\
$p_{r}{ }^{I}$ & Price of investment demand in region $r$ \\
$p_{r}{ }^{G}$ & Price of government demand in region $r$ \\
$p_{r}{ }^{C}$ & Price of aggregate household consumption in region $r$ \\
$p_{r}^{E C}$ & Price of aggregate household energy consumption in region $r$ \\
$w_{r}$ & Wage rate in region $r$ \\
$v_{r}$ & Price of capital services in region $r$ \\
$q_{i r}$ & Rent to natural resources in region $r(i \in F F)$ \\
$p^{w}$ & Real exchange rate with the rest of the world \\
$t_{r}{ }^{c}$ & Carbon tax in region $r$
\end{tabular}

Table A.3 Sets

\begin{tabular}{cl}
\hline$i$ & Sectors and goods \\
$j$ & Aliased with $i$ \\
$r$ & EU regions \\
$s$ & Aliased with $r$ \\
$E G$ & All energy goods: Coal, crude oil, refined oil, gas and electricity \\
$F F$ & Primary fossil fuels: Coal, crude oil, and gas \\
$L Q$ & Liquid fuels: Crude oil, refined oil and gas \\
$d$ & Demand categories: $Y=$ =intermediate, $C=$ household, and $I=$ investment. \\
\hline
\end{tabular}


Table A.4 Cost shares

$\theta_{i r s}^{X} \quad$ Share of exports from sector $i$ in region $r$ to region $s(i \notin F F)$

$\theta_{i r}^{W} \quad$ Share of exports from sector $i$ in region $r$ to the rest of the world $(i \notin F F)$

$\alpha_{i r}^{L} \quad$ Share of labor in value added in sector $i$ and region $r(i \notin F F)$

$\theta_{j i r} \quad$ Share of intermediate good $j$ in sector $i$ and region $r(i \in F F)$

$\theta_{i r}^{K L E} \quad$ Share of KLE aggregate in sector $i$ and region $r(i \in F F)$

$\theta_{i r}^{E} \quad$ Share of energy in the KLE aggregate of sector $i$ and region $r(i \in F F)$

$\theta_{i r}^{Q} \quad$ Share of natural resources in sector $i$ and region $r(i \in F F)$

$\theta_{j i r}^{F F} \quad$ Share of intermediate $\operatorname{good} j$ in sector $i$ of region $r(i \in F F)$

$\delta_{i r}^{L} \quad$ Share of labor in sector $i$ and region $r(i \in F F)$

$\delta_{i r}^{K} \quad$ Share of capital in sector $i$ and region $r(i \in F F)$

$\theta_{i r}^{C O} \quad$ Share of coal in energy demand by sector $i$ in region $r(i \notin F F)$

$\theta_{i r}^{E L} \quad$ Share of electricity in non-coal energy demand by sector $i$ in region $r(i \notin F F)$

$\beta_{j i r} \quad$ Share of fossil fuel $j$ in energy demand by sector $j$ in region $r(i \notin F F, j \in L Q)$

$\theta_{i s r}^{M} \quad$ Share of imports of good $i$ from region $s$ to region $r(i \notin F F)$

$\theta_{d i r}^{A} \quad$ Share of domestic variety $i$ in Armington aggregate for demand category $d$ for good $i$ in region $r$

$\theta_{i r}^{I} \quad$ Share of good $i$ in investment in region $r$

$\theta_{i r}^{G} \quad$ Share of good $i$ in government demand in region $r$

$\lambda_{r}^{E C} \quad$ Share of energy in aggregate household consumption in region $r$

$\gamma_{i r} \quad$ Share of non-energy good $i$ in non-energy household consumption demand in region $r$

$\lambda_{r}^{E L} \quad$ Share of electricity in aggregate household energy consumption in region $r$

$\lambda_{i r}^{E} \quad$ Share of non-electric energy-good $i$ in the non-electric household energy consumption in region $r$

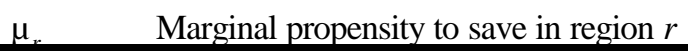

Table A.5 Endowments and emissions coefficients

\begin{tabular}{cl}
\hline$a_{d j r}^{c}$ & Carbon emissions coefficient for fossil fuel $j$ in demand category $d$ of region $r(j \in F F)$ \\
$\frac{L_{r}}{K_{r}}$ & Aggregate labor endowment in region $r$ \\
$\frac{Q_{i r}}{\overline{G_{r}}}$ & Aggregate capital endowment in region $r$ \\
$\overline{B_{r}}$ & Aggregate government demand in region $r$ \\
$\overline{Z_{r}}$ & Balance of payment surplus in region $r$ \\
\hline
\end{tabular}


Table A.6 Elasticities

$\eta \quad$ Transformation between production for the domestic and export markets

$\sigma_{K L E} \quad$ Substitution between energy and value-added in non-fossil fuel production

$\sigma_{Q} \quad$ Substitution between natural resources and other inputs in fossil fuel production

$\rho \quad$ Supply in fossil fuel production

$\sigma_{C O} \quad$ Substitution between coal and the non-coal energy in non-fossil fuel production

$\sigma_{E L} \quad$ Substitution between electricity and the non-coal fossil fuels in non-fossil fuel production

$\sigma_{M} \quad$ Substitution between imports from different regions

$\sigma_{A} \quad$ Substitution between the import aggregate and the domestic good

$\sigma_{E C} \quad$ Substitution between energy and non-energy in household consumption

$\sigma_{E L} \quad$ Substitution between electricity and the non-electric energy in household energy consumption

$\sigma_{N E} \quad$ Substitution between non-electric energy in household energy consumption 


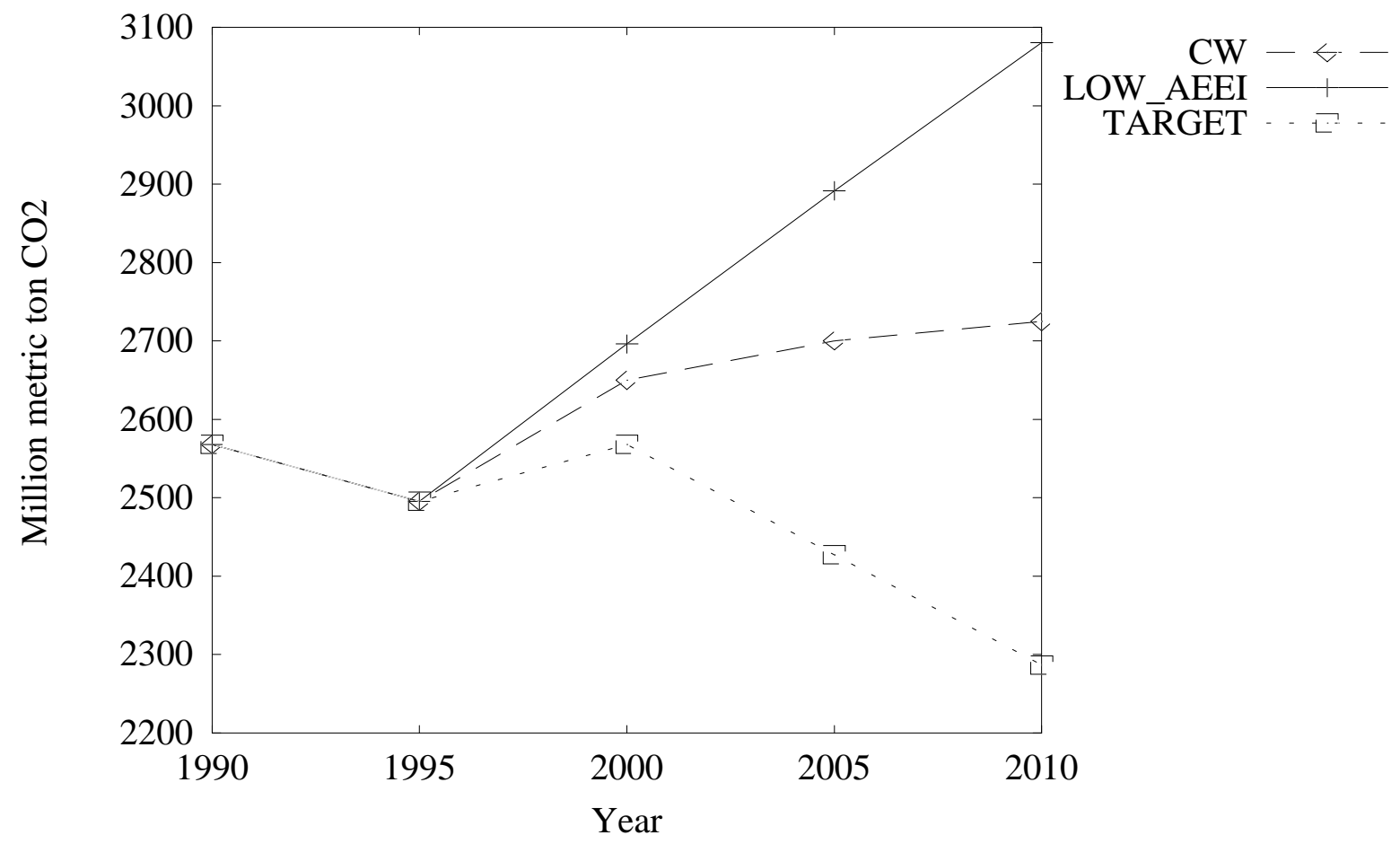

Figure 1. Emissions profiles

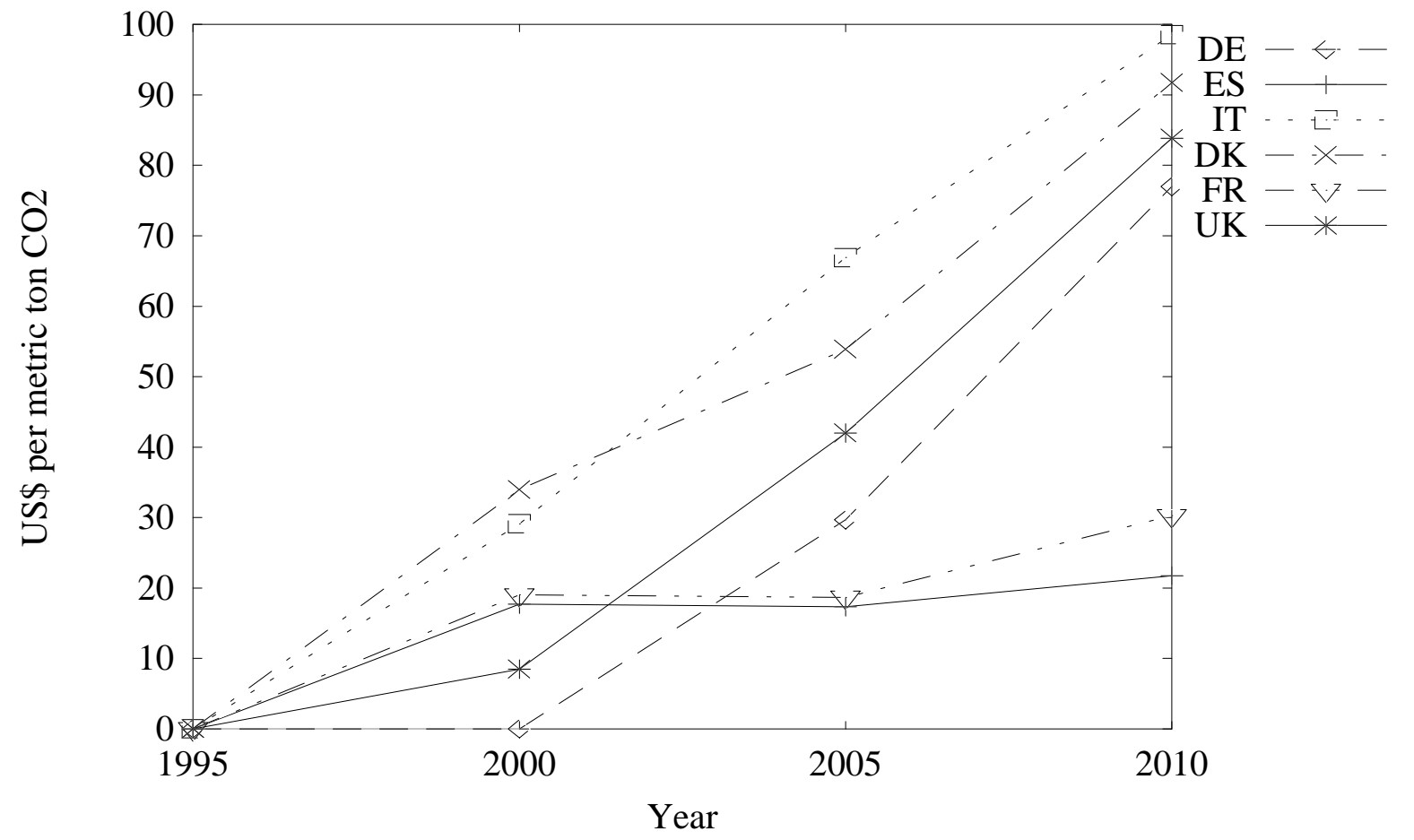

Figure 2. Carbon tax rates in the KYOTO scenario 


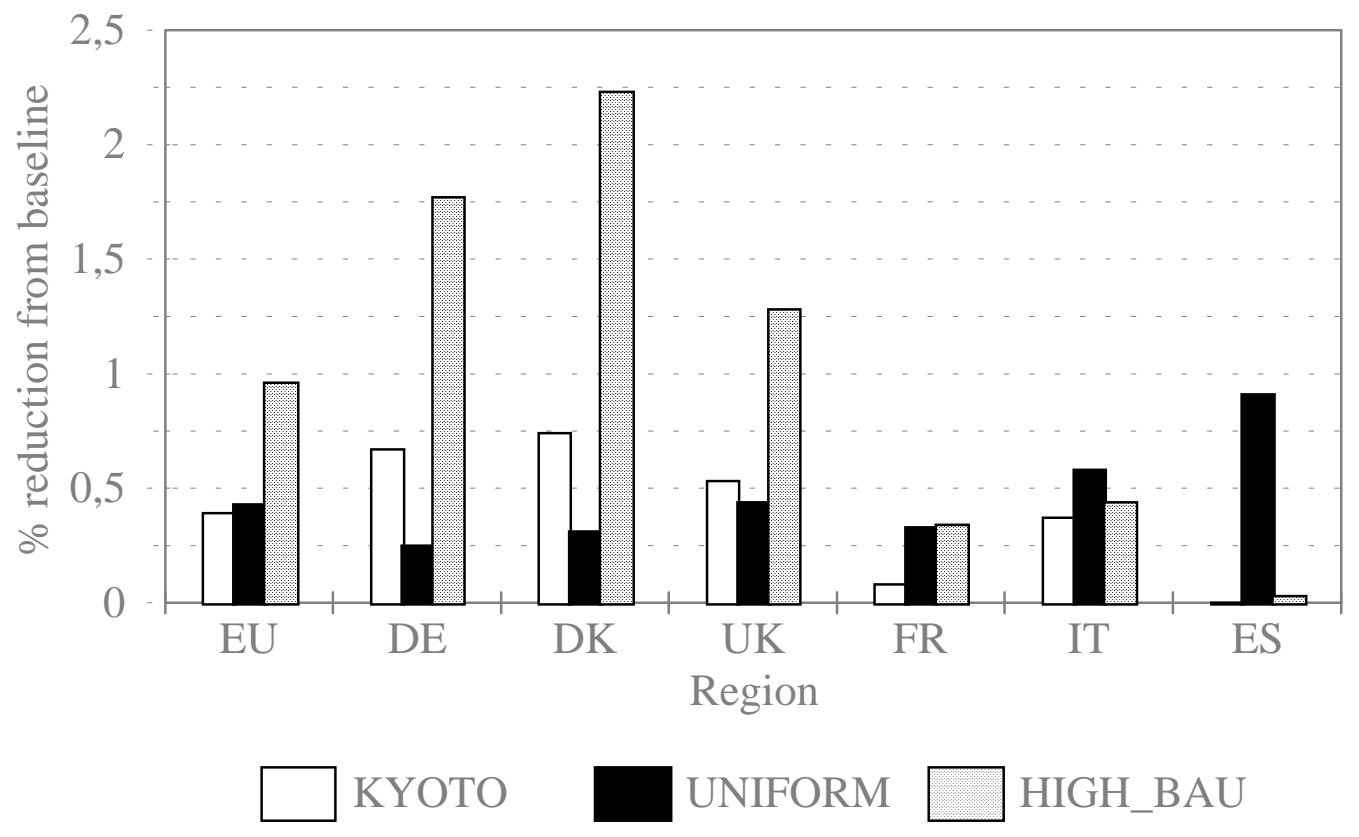

Figure 3. Consumption losses in 2010

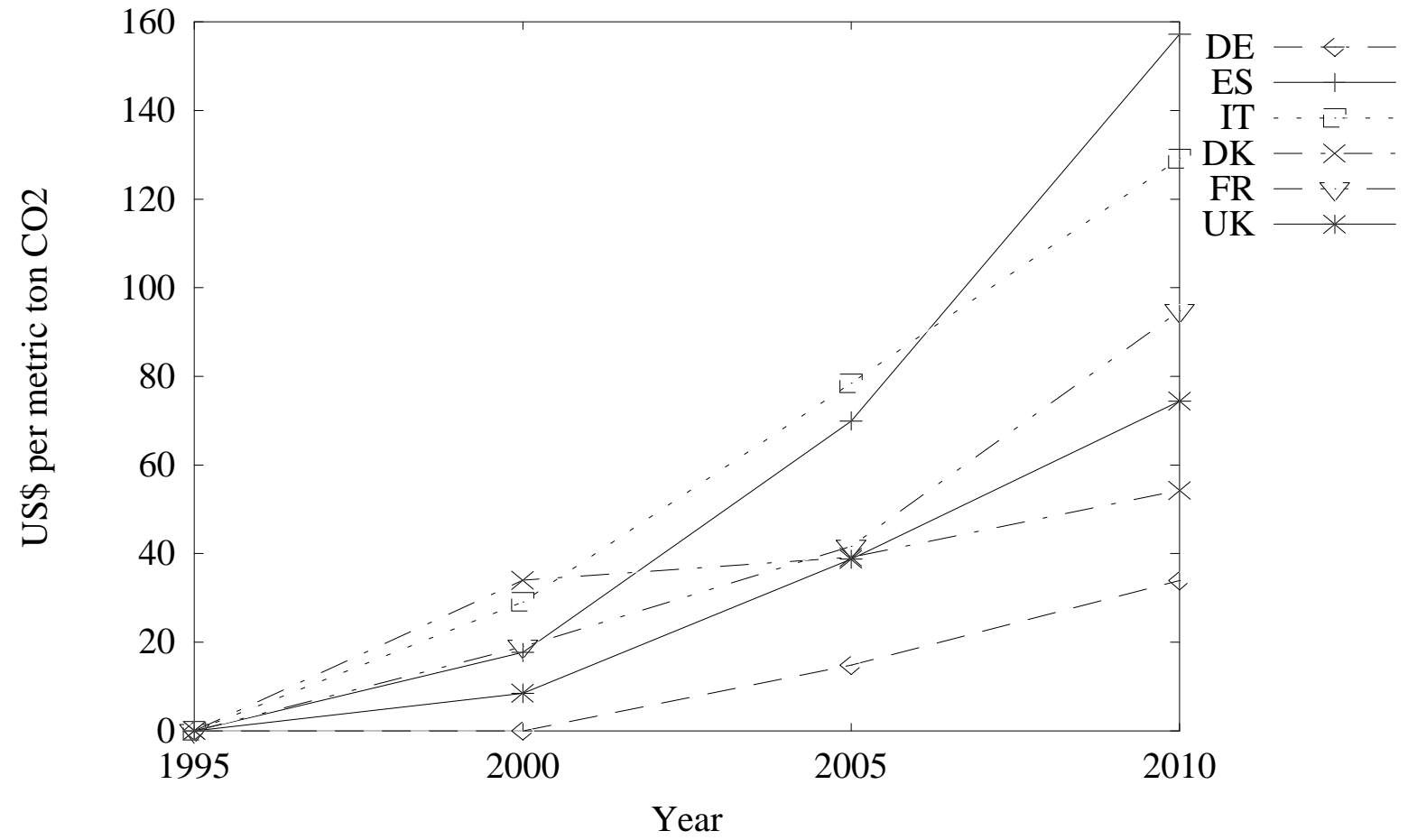

Figure 4. Carbon tax rates in the UNIFORM scenario 


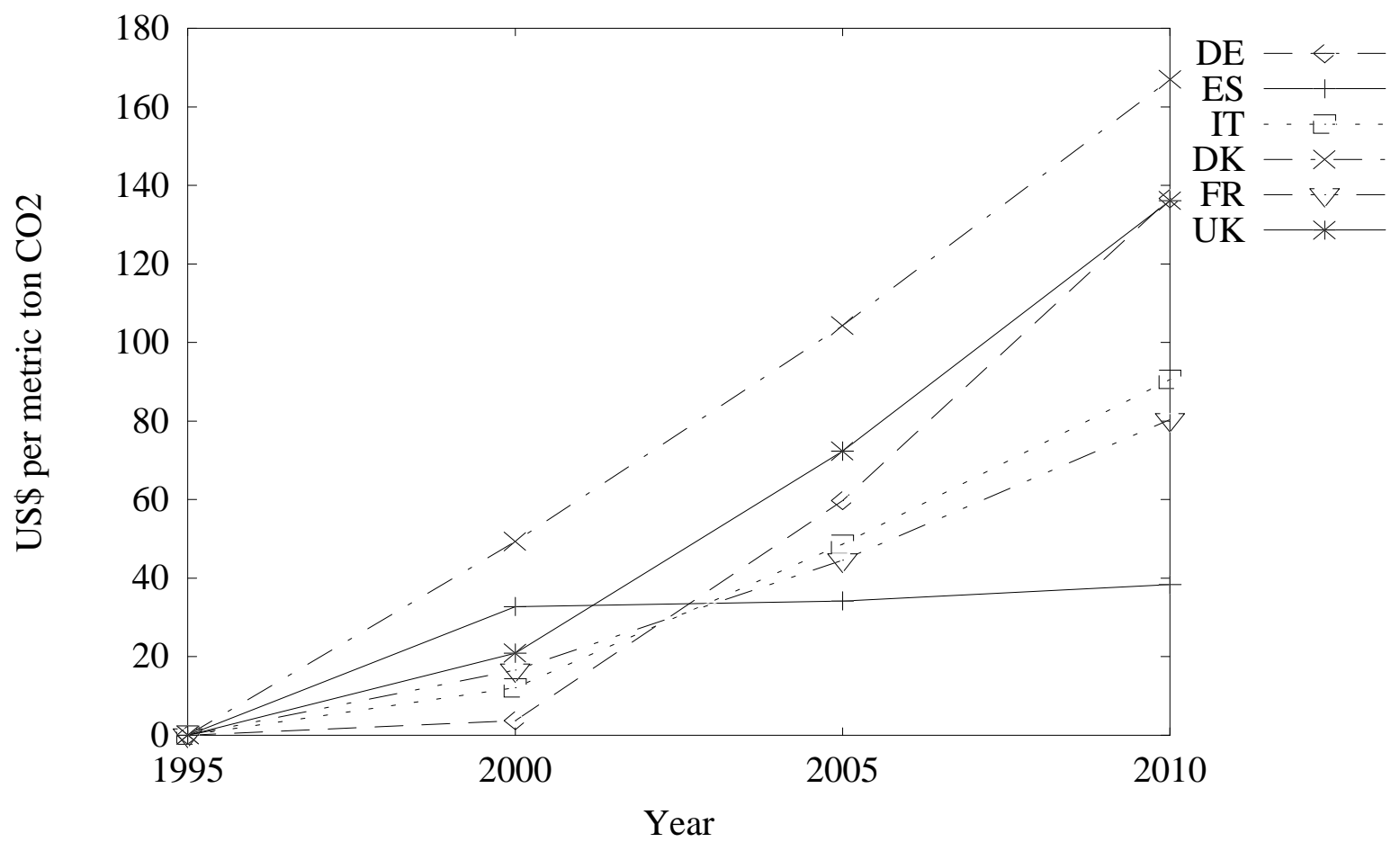

Figure 5. Carbon tax rates in the HIGH_BAU scenario 